OPEN ACCESS

Edited by:

Christian Albert Devaux, Centre National de la Recherche Scientifique (CNRS), France

Reviewed by: Jacques Fantini,

Aix Marseille Université, France Eric Lazartigues, Louisiana State University,

United States

${ }^{*}$ Correspondence:

Fei Chen

chenfei0336@163.com orcid.org/0000-0002-2578-7159

Specialty section:

This article was submitted to Virus and Host.

a section of the journal

Frontiers in Cellular and

Infection Microbiology

Received: 24 August 2021 Accepted: 28 September 2021

Published: 22 October 2021

Citation:

Chen F, Zhang Y, Li X, Li W, Liu X and Xue $X$ (2021) The Impact of ACE2

Polymorphisms on COVID-19 Disease: Susceptibility,

Severity, and Therapy.

Front. Cell. Infect. Microbiol. 11:753721. doi: 10.3389/fcimb.2021.753721

\section{The Impact of ACE2 Polymorphisms on COVID-19 Disease: Susceptibility, Severity, and Therapy}

\author{
Fei Chen *, Yankun Zhang, Xiaoyun Li, Wen Li, Xuan Liu and Xinyu Xue \\ Department of Physiology, Jining Medical University, Jining, China
}

The coronavirus disease 2019 (COVID-19), caused by severe acute respiratory syndrome coronavirus 2 (SARS-CoV-2), has currently spread worldwide, leading to high morbidity and mortality. As the putative receptor of SARS-CoV-2, angiotensin-converting enzyme 2 (ACE2) is widely distributed in various tissues and organs of the human body. Simultaneously, ACE2 acts as the physiological counterbalance of ACE providing homeostatic regulation of circulating angiotensin II levels. Given that some ACE2 variants are known to cause an increase in the ligand-receptor affinity, their roles in acquisition, progression and severity of COVID-19 disease have aroused widespread concerns. Therefore, we summarized the latest literature and explored how ACE2 variants and epigenetic factors influence an individual's susceptibility to SARS-CoV-2 infection and disease outcome in aspects of ethnicity, gender and age. Meanwhile, the possible mechanisms for these phenomena were discussed. Notably, recombinant human ACE2 and ACE2-derived peptides may have special benefits for combating SARSCoV-2 variants and further studies are warranted to confirm their effects in later stages of the disease process. As the uncertainty regarding the severity and transmissibility of disease rises, a more in-depth understanding of the host genetics and functional characteristics of ACE2 variants will not only help explain individual clinical differences of the disease, but also contribute to providing effective measures to develop solutions and manage future outbreaks of SARS-CoV-2.

Keywords: COVID-19, SARS-CoV-2, ACE2, variants, gene polymorphism, susceptibility, hrsACE2

\section{INTRODUCTION}

Coronavirus disease 2019 (COVID-19) poses a tremendous threat to human health. As of 4 August 2021, the infection has its presence around the globe with over 199 million of the world population being infected and has claimed over 4 million lives and counting (WHO, 2021). Severe acute respiratory syndrome coronavirus 2 (SARS-CoV-2), the virus causing COVID-19, is closely related to SARS-CoV with above $85 \%$ identity (Gralinski and Menachery, 2020). Similar to SARS-CoV, the entry of SARS-CoV-2 into the host cell is mediated by the surface-anchored spike (S) glycoprotein (Figure 1). The protein has two functional units known as "S1" and "S2", which are responsible for receptor binding and membrane fusion respectively. The receptor-binding domain (RBD) in the S1 binds to the extracellular peptidase domain (PD) of angiotensin-converting enzyme 2 (ACE2), 


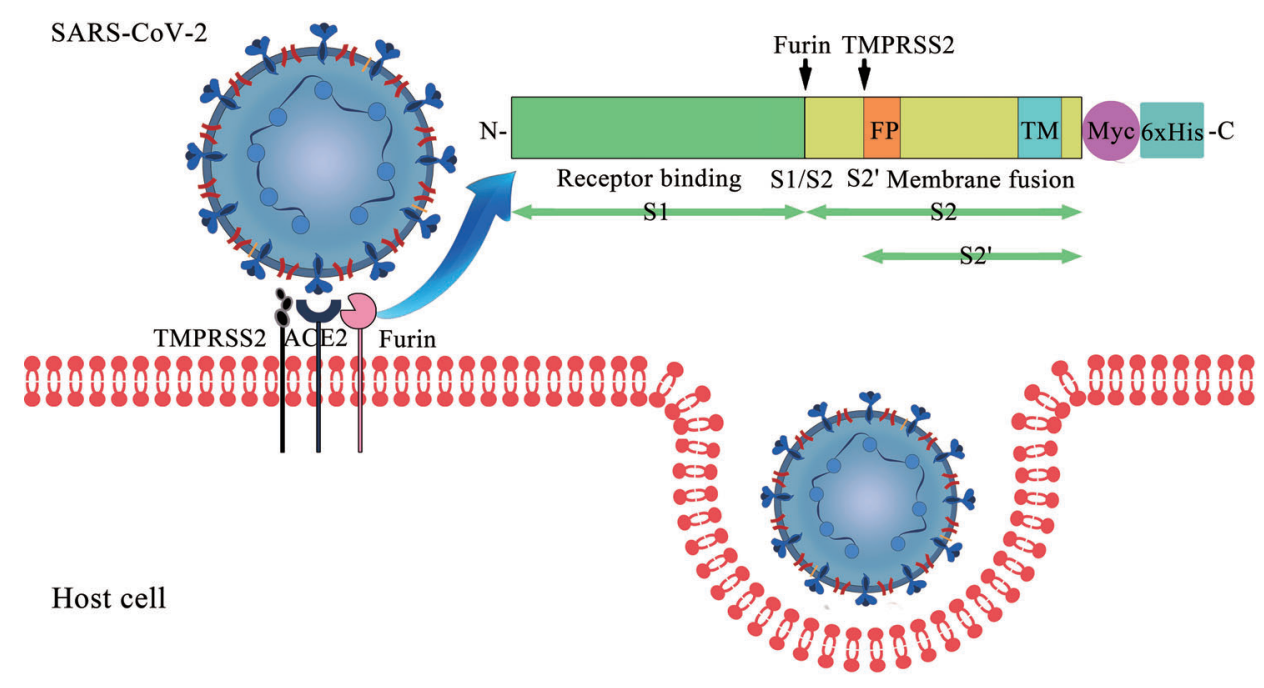

FIGURE 1 | Cell entry of SARS-CoV-2: the interaction between S protein and membrane ACE2.

which leads to the exposure of S1/S2 interdomain protease site. Then, the $\mathrm{S}$ protein is cleaved by the proprotein convertase furin at the $\mathrm{S} 1 / \mathrm{S} 2$ site and the transmembrane serine protease 2 (TMPRSS2) at the S2 site (Bestle et al., 2020). These processes facilitate large-scale conformational changes, triggering the fusion reaction by insertion of the fusion peptide of S2 into the host membrane (Suryamohan et al., 2021). The viral RNA is released for replication and translation upon the internalization of the SARS-CoV-2. Subsequently, new viruses are assembled and released from the cell to start another infection cycle.

As a functional receptor of SARS-CoV-2, full-length ACE2 is a $120-\mathrm{KDa}$ typical zinc-metalloproteinase type I transmembrane protein, which consists of an N-terminal signal peptide of 17 amino acid residues, a PD with its $\mathrm{HEXXH}+\mathrm{E}$ zinc-binding consensus sequence and a C-terminal Collectrin-like domain (Devaux et al., 2020a). It has two states, i.e. open and closed. In the open state, ACE2 opens widely from its active site, waiting for a ligand to enter. Once the ligand enters ACE2 active site, it will trigger ACE2 to close the active slot (Guo et al., 2020). ACE2 is expressed in essentially all tissues, with the highest expression in the small intestine, kidneys, testis, thyroid, heart, and adipose tissue followed by liver, lungs, colon, bladder, and adrenal gland (Li et al., 2020). Besides, there is another functional form of ACE2 with 555 amino acids that circulates in small amounts in the blood, named soluble ACE2 (sACE2), which is obtained by shedding of the full-length ACE2 through metalloproteinase 17 (ADAM17). It is worth emphasizing that binding of sACE2 to SARS-CoV-2 blocks the entry of the virus into the target cells and consequently, prevents the progression of COVID-19. Up to now, three major ACE2 functions have been described. In addition to being the viral receptor, ACE2 exhibits a protective role in the cardiovascular system and many other organs and contributes to the absorption of neutral amino acids in intestine (Kuba et al., 2010).
The ACE2 gene and protein show a high degree of genetic polymorphisms including single nucleotide variation, transcriptional variation, post-transcriptional modifications and putative protein mutations (Devaux et al., 2020a), among which single nucleotide polymorphisms (SNPs) has made its way to the scientific spotlight. Recently, Suryamohan et al. (2021) found 298 unique protein-altering variants across 256 codons distributed throughout the 805 amino acid long human ACE2 (hACE2) from a number of databases (Suryamohan et al., 2021). It is noteworthy that the symptoms and severity of COVID-19 vary greatly, ranging from very mild or no symptoms to pneumonia, acute respiratory distress syndrome (ARDS), and even death (Lopera Maya et al., 2020). As SARS-CoV-2 primarily depends on ACE2 for fusion and entry, ACE2 variation is considered to be one of the causes for this difference. Thus, it's important to systematically characterize and evaluate ACE2 polymorphism. Herein, this review provides an update on the possible role of ACE2 variants in both the susceptibility of people to SARS-CoV-2 infection and the outcome of COVID-19. Meanwhile, particular attention is given to ACE2-based potential therapeutic strategies.

\section{ALTERED AFFINITY OF ACE2 VARIANTS FOR S PROTEIN}

Considering that close and stable contact is crucial for RBD recognition, residue changes of $\mathrm{ACE} 2$ in the binding interface would influence affinity that is one of the most important determinants of host susceptibility. K353 and K31 in hACE2, which have been shown to be the main hotspots that form hydrogen bonds with the main chain of N501 and Q493 in receptor-binding motif respectively, play a role in tightly binding to the S protein of SARS-CoV-2 (Sehailia and Chemat, 2020). 
Due to possessing identical or similar critical residues, ACE2 molecules from pigs, ferrets, cats, orangutans and monkeys could bind to SARS-CoV-2 RBD with analogous efficiency (Wan et al., 2020). However, the presence of N30 (instead of D30) and N31 (instead of K31) in mouse ACE2 would cause the lack of salt bridges and critical H-bond in the ACE2-SARS-COV-2 RBD complex. In terms of rats, although E26 (instead of K26) in the ACE2 forms a salt bridge with $\mathrm{K} 417$ in RBD, it drives the relative movement of RBD over the rat ACE2 (a shift of $6.5 \AA$ comparing to its relative position in the human complex) and contributes to a decrease in the affinity of the virus to the ACE2 receptor (Brooke and Prischi, 2020). Another hotspot residue, K353, was replaced by histidine in mice and rats, leading to unfavorable bind with the SARS-CoV-2 RBD (Gao and Zhang, 2020). Thus, ACE2 receptor polymorphism can predict species susceptibility to SARS-CoV-2 to some extent (Devaux et al., 2020b). Although pigs and ferrets can be infected with SARS-CoV-2, they generally have a large size and a long growth cycle that is difficult to process in large quantities. Given the rapid emergence of virus mutations and novel vaccine candidates, there is a continuous need for genetic-modified mouse/rat models with the high tissue-specificity of hACE2 expression and susceptibility to SARS-CoV-2 infection.

Even if a total of more than 4 billion vaccine doses have been administered at present, COVID-19 is still spreading rapidly around the world with risk factors for infection including race/ethnicity, ages and both sexes. Thus, it is particularly important to pay close attention to the genetic variation of hACE2. The majority of the ACE2 coding variants found in Genome Aggregation Database (gnomAD) are missense variants that can alter amino acid sequence of the encoded protein, and ultimately result in a change of protein structure. Ser19, situated at the beginning of the helix S19-I54, forms hydrogen bonds with Glu23 and Gln24 to stabilize the helical structure and may interact with the S477 in S protein via weak hydrophilic interaction. Its mutation to proline would destabilize the helix structure and consequently influence the recognition by SARS-CoV-2 (Guo et al., 2020). Based on the OncoMX (https:// oncomx.org/) and gnomAD (https://gnomad.broadinstitute.org/) datasets, we compared 23 ACE2 variants with different allele frequencies in European (non-Finnish) and East Asian (Table 1). It is shown that 14 ACE2 variants (I21V, E23K, K26R, N64K, T92I, Q102P, D206G, G211R, R219C, E329G, H378R, V447F, A501T and N720D) with enhanced susceptibility have higher allele frequencies in European (non-Finnish) populations than East Asian populations, and 2 ACE2 variants (E35K and F72V) which offer resistance have higher allele frequencies in East Asian populations while they are low or not expressed in European (non-Finnish) populations. These findings are consistent with the epidemic situation and could partially account for the differences between COVID-19 prevalence and mortality rates in Europe and East Asia.

Notably, there are still controversial issues in results of binding affinity of $S$ protein for the same ACE2 receptor among studies. Suryamohan et al. (2021) and Wang et al. (2020) predicted that S19P, T27A and M82I enhanced ACE2 affinity whereas E37K, G326E, G352V and D355N exhibited decreased binding to RBD of S protein (Wang et al., 2020;
Suryamohan et al., 2021). In contradiction to their results, another group has reported that all these variants were found to have no obvious changes in the binding energy scores (Othman et al., 2020). These discrepancies may be attributed to different criteria and methods used by various researchers. Utilizing 5 fast structure-based computational approaches, HadiAlijanvand and Rouhani (2020) reported the predicted affinities of 240 mutated versions of ACE2 with the SARS-CoV-2 Spike protein, and there were varying degrees of difference in these prediction results. Particularly, the predicted stabilities of 211 ACE2 variant/S1 complexes obtained using SEPAS and SAAMBE-3D methods were different, among which 101 were completely opposite (Hadi-Alijanvand and Rouhani, 2020). As these methods considered different structural aspects of protein complexes, the observed inconsistency in prediction seems natural. Therefore, to better identify the risk variant in ACE2 and develop genetic diagnostic risk profiling for COVID-19 susceptibility, it is essential not only to develop more accurate methods that consider the dynamic features of protein structures, but also to perform more validation studies in vitro.

\section{SEX AND AGE DIFFERENCES IN ACE2 POLYMORPHISMS}

In the early pandemic, it was generally believed morbidity and lethality were higher in men compared with women. Although the available data indicate similar SARS-CoV-2 infection rates between the genders, males account for a greater percentage of deaths in most countries throughout the world, including China (approximately 64\% male: 36\% female), France $(57.83 \%$ : 42.17\%), Italy (56.43\%: 43.57\%), America (54.85\%: $45.15 \%$ ) and England (54.44\%: 45.56\%) (Global Health 50/50). As is well known, genetic variants of ACE, angiotensinogen and angiotensin II (Ang II) receptor genes show more profound effects in men, some of which are only positive in them. Therefore, apart from a higher prevalence of smoking and a deadly symbiosis of chronic systemic inflammation produced by chronic metabolic disease (such as obesity, metabolic syndrome and type 2 diabetes) in males (Mauvais-Jarvis, 2020) and a stronger innate and adaptive immune response to contagions in females, it is conceivable that ACE2 and its genetic variants also display gender-specific effects, which might be more decisive than epigenetic regulation for SARS-CoV-2 progression. For most $\mathrm{X}$-chromosome genes, the dosage difference between $\mathrm{XX}$ females and XY males is balanced by silencing one of the two $\mathrm{X}$ chromosomes in females in early development. However, the ACE2 gene is located on Xp22.2, an area where genes could escape this $\mathrm{X}$-inactivation, resulting in phenotypic differences between sexes. In males, the 16 residues of RBD carried by SARS$\mathrm{CoV}-2$, are in contact with 16 out of 20 residues of ACE2 protein (Lan et al., 2020). In females, the same SARS-CoV-2 RBD can be recognized by ACE2 on either of the two X chromosomes while cannot perfectly bind to the same residue sequences of ACE2 on the second chromosome theoretically, allowing unbound ACE2 to catalyze the cleavage of Ang II to form Ang-(1-7), and thus 
TABLE 1 | Allele frequencies of ACE2 variants with altered affinity in European (non-Finnish) and East Asian.

\begin{tabular}{|c|c|c|c|c|c|c|c|}
\hline Variant & Wild aa & Position & Mutant aa & Effect on affinity & Direct or indirect & European (non-Finnish) & East Asian \\
\hline rs778030746 & 1 & 21 & V & $\uparrow$ & Indirect & 0.00002446 & 0.000 \\
\hline rs756231991 & $E$ & 23 & K & $\uparrow$ & Indirect & 0.00001222 & 0.000 \\
\hline rs4646116 & $\mathrm{K}$ & 26 & $R$ & $\uparrow$ & Direct & 0.005868 & 0.00006738 \\
\hline rs1348114695 & $E$ & 35 & K & $\downarrow$ & Direct & 0.00001221 & 0.0001444 \\
\hline rs1192192618 & Y & 50 & $\mathrm{~F}$ & $\downarrow$ & Indirect & 0.00001227 & 0.000 \\
\hline rs1569243690 & $\mathrm{N}$ & 51 & $S$ & $\downarrow$ & Indirect & 0.00001229 & 0.000 \\
\hline rs1325542104 & M & 62 & V & $\downarrow$ & Indirect & 0.00001266 & 0.000 \\
\hline rs1199100713 & $\mathrm{N}$ & 64 & $\mathrm{~K}$ & $\uparrow$ & - & 0.00001081 & 0.000 \\
\hline rs1256007252 & $\mathrm{F}$ & 72 & V & $\downarrow$ & Indirect & 0.000 & 0.00007243 \\
\hline rs763395248 & $\mathrm{T}$ & 92 & I & $\uparrow$ & Direct & 0.00002448 & 0.000 \\
\hline rs1395878099 & $Q$ & 102 & $\mathrm{P}$ & $\uparrow$ & - & 0.00002168 & 0.000 \\
\hline rs142443432 & $\mathrm{D}$ & 206 & $G$ & $\uparrow$ & - & 0.0006314 & 0.000 \\
\hline rs148771870 & $G$ & 211 & $\mathrm{R}$ & $\uparrow$ & - & 0.001944 & 0.000 \\
\hline rs372272603 & $\mathrm{R}$ & 219 & C & $\uparrow$ & - & 0.0006950 & 0.000 \\
\hline rs143936283 & $E$ & 329 & $G$ & $\uparrow$ & - & 0.00006510 & 0.000 \\
\hline rs370610075 & $G$ & 352 & V & $\downarrow$ & Direct & 0.00001274 & 0.000 \\
\hline rs961360700 & $\mathrm{D}$ & 355 & $\mathrm{~N}$ & $\downarrow$ & Indirect & 0.00002591 & 0.000 \\
\hline rs142984500 & $\mathrm{H}$ & 378 & $\mathrm{R}$ & $\uparrow$ & - & 0.0001950 & 0.000 \\
\hline rs762890235 & $P$ & 389 & $\mathrm{H}$ & $\downarrow$ & - & 0.00002453 & 0.000 \\
\hline rs776328956 & V & 447 & $\mathrm{~F}$ & $\uparrow$ & - & 0.00007882 & 0.000 \\
\hline rs191860450 & 1 & 468 & V & $\uparrow$ & - & 0.00002198 & 0.01140 \\
\hline rs140473595 & $A$ & 501 & $\mathrm{~T}$ & $\uparrow$ & - & 0.00004746 & 0.000 \\
\hline rs41303171 & $\mathrm{N}$ & 720 & $D$ & $\uparrow$ & - & 0.02521 & 0.000 \\
\hline
\end{tabular}

reducing unregulated inflammatory lung damage. With a single $\mathrm{X}$ chromosome, men lack the alternative mechanisms of organ protective functions. In addition, males are hemizygous for the ACE2 gene, but in females, the rate of homozygous for variants was extremely low and $98.3 \%$ of missense variants were heterozygous, implicating that the efficacy of interactionbooster variants of ACE2 can be stronger in men than women. An analysis revealed that 7 of 10 interaction-booster variants (S19P, K26R, I21V, I21T, N64K, H378R, and T92I) were expressed in males, which means more than half of the variants have the opportunity to affect the interaction between the hACE2 and S1 protein of SARS-COV-2 (Darbani, 2020). Nevertheless, the current data is not able to determine a clear causality, and as most of the identified variants have very low frequencies, further functional studies are needed to verify these results.

The high incidence of COVID-19 in the elderly is also associated with increased expression of ACE2 (Pruimboom, 2020). In children, the ACE 2 gene in the lungs, oral tissues, and other organs is ordinarily hypermethylated and therefore actually silent (Pruimboom, 2020). Nevertheless, highthroughput, next-generation sequencing technologies and microarray revealed an increase in variability of DNA methylation with age, which caused certain genes to gradually become more active during the aging process. For example, DNA methylation at one CpG (cg08559914) near the transcription start site of the ACE2 gene in airway epithelial cells is inversely correlated with biological age (Corley and Ndhlovu, 2020). In addition, a previous study showed that ACE2 expression is also transcriptionally regulated by adenosine monophosphate kinase via sirtuin 1 (SIRT1) (Patel et al., 2016), and exogenous zinc strongly inhibits SIRT1 activity (Chen et al., 2010), hence, regulation of SIRT1 by zinc may decrease ACE2 expression and ultimately SARS-CoV-2 entry into the cell. However, some evidence indicates that zinc intakes among older adults might be marginal. An analysis of the third National Health and Nutrition Examination Survey data found that $35 \%$ to $45 \%$ of people over 60 years old had zinc intakes below the estimated average (Ervin and Kennedy-Stephenson, 2002). Notably, anosmia and ageusia, previously thought to be pathognomonic of zinc deficiency, are now also considered early signs of COVID-19, suggesting the presence of common mechanisms.

Mortality rates of COVID-19 vary dramatically across age groups. Compared with 18- to 29-year-olds, the rate of death is 95 times higher in 65- to 74-year-olds, 230 times higher in 75- to 84 -year-olds, and 600 times higher in those who are 85 years and older (Centers for Disease Control and Prevention, 2021). Apart from chronic conditions and a dysregulated immune system with aging, other possible explanations for this phenomenon are as follows: (1) The vast majority of deaths result from ARDS with the histologic finding of diffuse alveolar damage (DAD). In response to DAD, type II pneumocytes enter the cell cycle and normally downregulate ACE2 expression (Baker et al., 2021). However, in the elderly suffering from COVID-19 or other diseases, the increased circulating inflammatory cytokines and age-associated epigenetic dysregulation preclude this downregulation or even lead to ACE2 upregulation, finally causing worse clinical outcomes. (2) The sACE2 levels are lower in the population over 60 years of age. In addition to the decreased Ang II/ADAM17 induced ACE2 shedding owing to the lower plasma renin concentration; some microRNAs (miRNAs) target the 3'-UTR, 5'-UTR or coding DNA sequence of ACE2 and influence its expression either by mediating complementary mRNA degradation or by interfering with translation. For example, miR-212-5p is significantly positively correlated with age and negatively related to sACE2 while miR- 
3909, the miRNA significantly negatively correlated with age, is positively related to sACE2 (Elemam et al., 2021). (3) As the active form of vitamin $\mathrm{D}$ (VitD), 1,25(OH)2D3 can induce ACE2/Ang-(1-7)/MasR axis activity and suppress renin and the ACE/Ang II/AT1R axis, thereby producing a potential protective role against ARDS. Over 60 years of age, a reduction in the synthesis of VitD in response to UVB becomes apparent, which further increases when getting older (Heaney, 2006).

\section{COMORBIDITIES AND ACE2 POLYMORPHISMS}

Although the T allele of ACE2 rs2106809 has been shown to be inversely correlated with severe malaria (De et al., 2021), accumulating evidence suggests that most ACE2 polymorphisms could lead to a variety of diseases, such as atrial fibrillation, hypertension, type 2 diabetes mellitus (T2D), cardiomyopathy and so on. A summary of these results (Lieb et al., 2006; Yi et al., 2006; Wang et al., 2008; Meng et al., 2015; He et al., 2018; Kumar et al., 2018; Liu C. et al., 2018; Pan et al., 2018; Luo et al., 2019; Lozano-Gonzalez et al., 2020; Liu et al., 2021) and related research is shown in Table 2. Notably, ethnicity has been proved to alter the link between ACE2 single nucleotide polymorphisms (SNPs) and some diseases. For example, among persons of British (rs1978124, rs2074192 and rs4646188) or Finnish (rs879922) descent, there is no correlation between ACE2 SNPs and T2D, however, all the four SNPs are dramatically relevant to T2D in Xinjiang Uygur. Similarly, the sex dimorphism is observed in the relationship between ACE2 SNPs and certain diseases. The left ventricular mass index of males with the minor alleles of three SNPs (rs879922, rs4240157 and rs233575) is higher than those who do not carry these SNPs, but this phenomenon is not observed in women. On the contrary, the association of ACE2 rs2106809 with blood pressure response to ACE inhibitor was identified only in women but not in men. Specifically, after 6 weeks of ACE inhibitor therapy, female patients carrying CC or CT genotype had a greater degradation of diastolic blood pressure compared with those carrying TT genotype (Chen Y. Y. et al., 2016). Therefore, it is reasonable to assume ACE2 variant rs2106809 T allele or some other SNPs in the same linkage disequilibrium block, may be functional and could decrease the sACE2 expression and increase the susceptibility to hypertension. Considering the double effect of sACE2 on hypertension and antiviral activity, this may partly explain the high incidence rate of hypertension (58\%) in critically ill patients with COVID-19 (Sulaiman et al., 2021). By the way, ACE2 rs2074192 T allele and rs2285666 G allele, which are listed in the Table 2, have been reported to be associated with more severe clinical outcomes of SARS-CoV-2 infection (Cafiero et al., 2021; Mohlendick et al., 2021). Thus, besides factors such as aging, vascular disorders and delayed virus clearance, variants-mediated risks are worth exploring in more detail. Additionally, lupus, diabetes and cancer are also comorbidities closely related to adverse outcomes or death. It is easy to understand this phenomenon because aberrant epigenetic modification of ACE2 gene is one of the characteristics of these diseases. DNA methylation defects in lupus patients (Sawalha et al., 2020), aggravated by oxidative stress generated from SARS-CoV-2 infection, could lead to ACE2 overexpression and enhance viral entry. Therefore, therapeutic strategies and drugs that efficiently target epigenetic modification should be considered in further research.

\section{ACE2-BASED PHARMACOTHERAPY FOR COVID-19}

Up to date, SARS-CoV-2 variant B.1.617 (Delta) has spread voraciously across more than 100 countries and its major mutation site, L452R, enhances infectivity by increasing the affinity of the S protein to the hACE2 (Deshpande et al., 2021). Tremendous advances have been made in vaccine development and nonpharmaceutical interventions to stop the spread of COVID-19 infection, but treatments to halt the progression of the disease are still limited. As a competitive interceptor of SARS$\mathrm{CoV}-2$ and other coronaviruses, sACE 2 can be used as a protective biomarker for rapid test screening, and even one of the treatment strategies. By the way, they are not affected by common escape mutations in viral proteins. However, in view of its low concentration in plasma, it's necessary to introduce exogenous forms. In in-vitro cell-culture experiments and engineered human organoids, an appropriate introduction of human recombinant soluble ACE2 (hrsACE2) reduced the SARS-CoV-2 growth by a factor of 1,000-5,000 (Monteil et al., 2020), directly demonstrating that this can significantly neutralize viruses. At the same time, no drug-related severe adverse events were observed in the tests of healthy volunteers and COVID-19 patients (Haschke et al., 2013). Interestingly, Khan et al. (2017) found that the infusion of hrsACE2 tends to decrease the interleukin-6 (IL-6) concentration in patients with ARDS (Khan et al., 2017). Given that the level of IL- 6 has a positive correlation with the severity of the disease, hrsACE2 is considered as a promising treatment option. However, the therapeutic potential of recombinant ACE2 (rACE2) for chronic use is restricted due to its short plasma half-life of only 1.8 hours. To circumvent this, rACE2-Fc is created by fusing rACE2 and an Fc fragment, with a plasma halflife of 174.2 hours and higher serum activity than rACE2 (Liu P. et al., 2018). Similarly, a C-terminally truncated hrsACE2 protein of 618 amino acids is fused with a small $(5-\mathrm{kD})$ albumin-binding domain (ABD) to form a new type termed ACE2 1-618-ABD (Wysocki et al., 2021). It offers a better way to prevent viral escape and affords more convenient dosing schedules compared with the native form of sACE2 1-740 currently undergoing clinical trials (NCT04335136). In addition, after viral binding, ACE2-ABD could direct the SARS-CoV-2-ACE2 complex to a different cell sorting pathway. When bound to albumin, it might direct the complex into the FcRn-mediated recycling pathway rather than the lysosome-endosome pathway that seems crucial for viral processing and replication.

Besides rACE2, ACE2-derived peptides corresponding to the ACE2-interacting domain of SARS-CoV-2 may represent an 
TABLE 2 | Association between ACE2 polymorphisms and human diseases/ symptoms in different populations.

Disease/Symptom Subjects' characteristic

Variant

Reference(s)

Cardiac event

\section{Higher risk of $\mathrm{AF}$}

Higher risk of $\mathrm{AF}$

Larger size of $L A D$

Lower LVEF

作

Higher parameters (LVMI and SWT) of LVH German men from the Augsburg area

Higher parameters (LVMI and SWT) of LVH Male HCM patients

DCM

Blood pressure disorder EH

$\mathrm{EH}$

Higher levels of SBP

Higher levels of SBP

Higher levels of DBP

Higher levels of DBP

Dyslipidemia

High LDL-C level

High LDL-C level

High $\mathrm{CHOL}$ level

High CHOL level

High TRIG level

High TRIG level

Low HDL-C level

Low HDL-C level

Ischemic stroke

Increased serum sodium level

Lower serum potassium concentration

CAS $\geq 50 \%$

CAS $\geq 50 \%$

CAS $\geq 50 \%$

T2D

Increased MAU level

Higher level of HsCRP

DR and PDR

SGA

13 ACE2 variants are shown in different colors and have been associated with different diseases or symptoms.

$A F$, atrial fibrillation; LAD, left atrial end-systolic diameter; $L V E F$, left ventricular ejection fraction; LVMI, left ventricular mass index; SWT, septal wall thickness; $L V H$, left ventricular hypertrophy; DCM, dilated cardiomyopathies; EH, essential hypertension; SBP, systolic blood pressure; DBP, diastolic blood pressure; LDL-C, low-density lipoprotein cholesterol; CHOL, cholesterol; TRIG, triglyceride; HDL-C, high-density lipoprotein cholesterol; CAS, carotid arteriosclerosis stenosis; T2D, type 2 diabetes; MAU, microalbuminuria; HsCRP, high-sensitivity C-reactive protein; DR, diabetic retinopathy; PDR, proliferative diabetic retinopathy; SGA, small-for-gestational-age; HCM, hypertrophic cardiomyopathy.

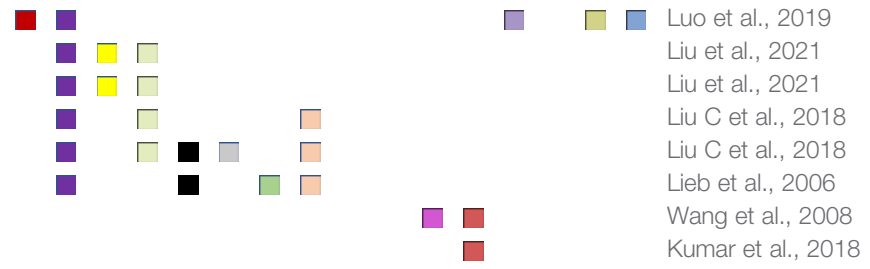

Subjects from the south Xinjiang

Dongxiang population

$\square$

Donors from Mexico City and surrounding states

Uighurs

Donors from Mexico City and surrounding states

Uighurs

Uygur T2D patients

Subjects from the south Xinjiang

Uygur T2D patients

Subjects from the south Xinjiang

Uygur T2D patients

Subjects from the south Xinjiang

Uygur T2D patients

Subjects from the south Xiniiang

Subjects from the south Xinjiang

Uygur T2D patients

Uygur T2D patients

EH subjects from the south Xinjiang

Uighurs

Uighurs

Uygur T2D patients

Jygur T2D patients

Chinese female T2D patients

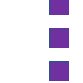

$\square$

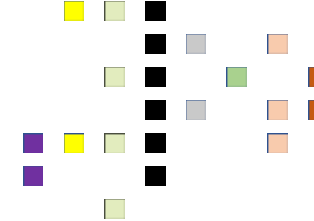

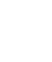

$\square$

Pan et al., 2018; Luo et al., 2019

Yi et al., 2006

Lozano-Gonzalez et al., 2020

Liu C et al., 2018

Lozano-Gonzalez et al., 2020

Liu et al., 2018

Liu et al., 2018

Pan et al., 2018

Liu C et al., 2018

Pan et al., 2018

Liu C et al., 2018

Pan et al., 2018

$\square$

Pan et al., 2018

Liu et al., 2021

Liu et al., 2021

Liu C et al., 2018

L Luo et al., 2019

Liu C et al., 2018

Liu C et al., 2018

Liu C et al., 2018

iu et al., 2021

Meng et al., 2015 $\square \square \square \square \square \square$ 
alternative strategy to target this pathway due to their relative safety, low production complexity and remarkable curative action. Through fusing the RBD-binding proteins to the CHIP $\triangle T P R$ modified E3 ubiquitin ligase domain, Chatterjee et al. (2020) designed 23-mer (A2N)-CHIPATPR fusion, and this ACE2derived peptide demonstrated robust $\mathrm{RBD}$ degradation capabilities in human cells and reduced the infection rate of the pseudovirus by $\sim 60 \%$ (Chatterjee et al., 2020). As for genuine
SARS-CoV-2, its infection has also been reported to be inhibited by Spike-targeting ACE2-derived peptide1 (SAP1) and SAP6 in affinity precipitation assays (Larue et al., 2021).

Of note, although most ACE2-based pharmacotherapies exhibit an acceptable safety profile and some of them have entered clinical trials (Table 3) (Zhong et al., 2011; Zou et al., 2014; Chen L. J. et al., 2016; Gu et al., 2016; Khan et al., 2017; Liu C. et al., 2018; Rathinasabapathy et al., 2018; Chatterjee et al., 2020;

TABLE 3 | A summary of the therapies based on ACE2 used until present.

\begin{tabular}{|c|c|c|c|c|c|c|c|c|}
\hline \multicolumn{2}{|c|}{ Primary drug } & \multirow{2}{*}{$\begin{array}{l}\text { Condition or } \\
\text { disease }\end{array}$} & \multirow{2}{*}{$\begin{array}{l}\text { Species } \\
\text { Mice (FVB/ } \\
\text { N) }\end{array}$} & \multirow{2}{*}{$\begin{array}{l}\text { Dosage } \\
\\
1.2 \mathrm{mg} / \\
\mathrm{kg} / \mathrm{day} \\
\times 14 \\
\text { days }\end{array}$} & \multirow{2}{*}{$\begin{array}{l}\begin{array}{c}\text { Medication } \\
\text { method }\end{array} \\
\text { Mini-osmotic } \\
\text { pumps }\end{array}$} & \multirow{2}{*}{$\begin{array}{l}\text { Results } \\
\text { Significantly attenuated vascular } \\
\text { remodeling and increased } \\
\text { pulmonary SOD2 expression } \\
\text { without measurable effects on } \\
\text { pulmonary fibrosis. }\end{array}$} & \multirow[t]{2}{*}{ Pros and Cons } & \multirow{2}{*}{$\begin{array}{l}\text { Reference } \\
\text { Rathinasabapathy } \\
\text { et al., } 2018\end{array}$} \\
\hline rACE2 & hrsACE2 & & & & & & & \\
\hline & hrsACE2 & COVID-19 & Human & $\begin{array}{l}2 \text { times/ } \\
\text { day }\end{array}$ & $\begin{array}{l}\text { Intravenous } \\
\text { injection }\end{array}$ & $\begin{array}{l}\text { Significant improvement in } \\
\text { mechanical ventilator-free Days } \\
\text { and reduction in viral RNA load } \\
\text { observed }\end{array}$ & - & Clinicaltrials, 2021 \\
\hline & hrsACE2 & $\begin{array}{l}\text { H5N1 } \\
\text { infection } \\
\text { induced } \\
\text { acute lung } \\
\text { injury }\end{array}$ & $\begin{array}{l}\text { Mice } \\
(\mathrm{BALB} / \mathrm{c})\end{array}$ & $\begin{array}{l}0.1 \mathrm{mg} / \\
\mathrm{kg} \times 3 \\
\text { times }\end{array}$ & $\begin{array}{l}\text { Intraperitoneal } \\
\text { injection }\end{array}$ & $\begin{array}{l}\text { Reduced acute lung injury } \\
\text { severity and prolonged overall } \\
\text { survival time of infected mice }\end{array}$ & - & Zou et al., 2014 \\
\hline & hrsACE2 & ARDS & Human & $\begin{array}{l}0.4 \mathrm{mg} / \\
\mathrm{kg} \times 2 \\
\text { times/ } \\
\text { day } \times 3 \\
\text { days }\end{array}$ & $\begin{array}{l}\text { Intravenous } \\
\text { injection }\end{array}$ & $\begin{array}{l}\text { Did not result in improvement in } \\
\text { physiological or clinical measures } \\
\text { of ARDS }\end{array}$ & $\begin{array}{l}\text { Causes some adverse events, } \\
\text { such as hypernatremia, } \\
\text { pneumonia, dysphagia and } \\
\text { rash. }\end{array}$ & Khan et al., 2017 \\
\hline & hrsACE2 & $\begin{array}{l}\text { Respiratory } \\
\text { syncytial virus } \\
\text { induced lung } \\
\text { injury }\end{array}$ & $\begin{array}{l}\text { Mice } \\
(\mathrm{C} 57 \mathrm{BL} / 6)\end{array}$ & $\begin{array}{l}0.1 \mathrm{mg} / \\
\mathrm{kg} \times 3 \\
\text { times }\end{array}$ & $\begin{array}{l}\text { Intravenous } \\
\text { injection }\end{array}$ & $\begin{array}{l}\text { Reduces the severity of lung } \\
\text { injury. }\end{array}$ & - & Gu et al., 2016 \\
\hline & hrsACE2 & $\begin{array}{l}\text { Ang II- } \\
\text { mediated } \\
\text { renal } \\
\text { oxidative } \\
\text { stress, } \\
\text { inflammation, } \\
\text { and fibrosis }\end{array}$ & $\begin{array}{l}\text { Mice } \\
\text { (C57BL/6) }\end{array}$ & $\begin{array}{l}2 \mathrm{mg} / \\
\mathrm{kg} / \text { day } \\
\times 14 \\
\text { days }\end{array}$ & $\begin{array}{l}\text { Intraperitoneal } \\
\text { injection }\end{array}$ & $\begin{array}{l}\text { Reversed renal NADPH oxidase } \\
\text { activation and } \\
\text { proinflammatory changes, and } \\
\text { attenuated tubulointerstitial } \\
\text { fibrosis }\end{array}$ & - & Zhong et al., 2011 \\
\hline & hrsACE2 & $\begin{array}{l}\text { Ang II- } \\
\text { induced renal } \\
\text { fibrosis }\end{array}$ & $\begin{array}{l}\text { Mice } \\
\text { (apoE-KO) }\end{array}$ & $\begin{array}{l}2 \mathrm{mg} / \\
\mathrm{kg} / \text { day } \\
\times 14 \\
\text { days }\end{array}$ & $\begin{array}{l}\text { Intraperitoneal } \\
\text { injection }\end{array}$ & $\begin{array}{l}\text { Dramatically ameliorated Ang II- } \\
\text { mediated hypertension, kidney } \\
\text { remodeling and tubulointerstitial } \\
\text { fibrosis }\end{array}$ & - & Chen et al., 2016a \\
\hline & rACE2-Fc & $\begin{array}{l}\text { Acute } \\
\text { hypertension }\end{array}$ & $\begin{array}{l}\text { Mice } \\
(\mathrm{BALB} / \mathrm{c})\end{array}$ & 4 kU/kg & $\begin{array}{l}\text { Intravenous } \\
\text { injection }\end{array}$ & $\begin{array}{l}\text { Significantly lowered SBP } \\
\text { following Ang II }\end{array}$ & $\begin{array}{l}\text { 1. With the same dose, the } \\
\text { peak blood concentration of }\end{array}$ & Liu P et al., 2018 \\
\hline & rACE2-FC & $\begin{array}{l}\text { Chronic } \\
\text { hypertension, } \\
\text { albuminuria } \\
\text { and } \\
\text { multiorgan } \\
\text { fibrosis }\end{array}$ & $\begin{array}{l}\text { Mice } \\
\text { (RenTgMK) }\end{array}$ & $\begin{array}{l}1 \text { time } / 7 \\
\text { days } \times \\
42 \text { days }\end{array}$ & $\begin{array}{l}\text { Intravenous } \\
\text { injection }\end{array}$ & $\begin{array}{l}\text { 1. Reduced endogenous plasma } \\
\text { Ang II levels } \\
\text { 2. The levels of BP and } \\
\text { albuminuria stayed within normal } \\
\text { ranges } \\
\text { 3. Reduced areas of fibrosis } \\
\text { 4. Reduced the levels of Akt and } \\
\text { Erk phosphorylation levels }\end{array}$ & $\begin{array}{l}\text { rACE2-Fc was 2-fold higher } \\
\text { than that of untagged rACE2 } \\
\text { and could be sustained for } \\
\text { much longer time. } \\
\text { 2. Infusion of rACE2-Fc did not } \\
\text { show any blood pressure- } \\
\text { lowering effect in normotensive } \\
\text { controls. }\end{array}$ & Liu P et al., 2018 \\
\hline & rACE2-FC & $\begin{array}{l}\text { Cardiac } \\
\text { hypertrophy } \\
\text { and fibrosis }\end{array}$ & $\begin{array}{l}\text { Mice } \\
\text { (C57BL/6) }\end{array}$ & $\begin{array}{l}1 \text { time } / 7 \\
\text { days } \times \\
28 \text { days }\end{array}$ & $\begin{array}{l}\text { Intravenous } \\
\text { injection }\end{array}$ & $\begin{array}{l}\text { Completely prevented SBP } \\
\text { increase, ventricular wall } \\
\text { thickening, heart enlargement, } \\
\text { cardiomyocyte diameter increase } \\
\text { and interstitial and perivascular } \\
\text { cardiac collagen deposition }\end{array}$ & $\begin{array}{l}\text { 3. It can pass through the } \\
\text { placental barrier and is } \\
\text { expected to contribute to Ang } \\
\text { II degradation during the } \\
\text { placental passage and in the } \\
\text { fetus. }\end{array}$ & Liu P et al., 2018 \\
\hline
\end{tabular}


TABLE 3 | Continued

\begin{tabular}{|c|c|c|c|c|c|c|c|c|}
\hline \multicolumn{2}{|c|}{ Primary drug } & \multirow{2}{*}{$\begin{array}{l}\text { Condition or } \\
\text { disease }\end{array}$} & \multirow[t]{2}{*}{ Species } & \multirow[t]{2}{*}{ Dosage } & \multirow{2}{*}{$\begin{array}{l}\text { Medication } \\
\text { method }\end{array}$} & \multirow[t]{2}{*}{ Results } & Pros and Cons & \multirow[t]{2}{*}{ Reference } \\
\hline & & & & & & & $\begin{array}{l}\text { 4. Long-acting rACE2-Fc may } \\
\text { help to address the "Ang II } \\
\text { escape" phenomena. }\end{array}$ & \\
\hline & $\begin{array}{l}\text { ACE2 1- } \\
618-A B D\end{array}$ & $\begin{array}{l}\text { SARS-CoV-2 } \\
\text { infection }\end{array}$ & $\begin{array}{l}\text { Human } \\
\text { kidney } \\
\text { organoids }\end{array}$ & $\begin{array}{l}0.2 \mathrm{mg} / \\
\mathrm{ml}\end{array}$ & - & Markedly reduced viral replication & $\begin{array}{l}\text { Prolonged duration of action } \\
\text { and afforded more convenient } \\
\text { dosing schedules. }\end{array}$ & $\begin{array}{l}\text { Wysocki et al., } \\
2021\end{array}$ \\
\hline & $\begin{array}{l}\text { ACE2 1- } \\
618-A B D\end{array}$ & $\begin{array}{l}\text { Acute } \\
\text { hypertension }\end{array}$ & $\begin{array}{l}\text { Mice } \\
\text { (C57BL/6) }\end{array}$ & $1 \mathrm{mg} / \mathrm{kg}$ & $\begin{array}{l}\text { Intraperitoneal } \\
\text { injection }\end{array}$ & $\begin{array}{l}\text { Significantly attenuated Ang II- } \\
\text { induced hypertension }\end{array}$ & & \\
\hline \multirow{4}{*}{$\begin{array}{l}\text { ACE2 } \\
\text { derived } \\
\text { peptides }\end{array}$} & $\begin{array}{l}\text { 23-mer } \\
(\mathrm{A} 2 \mathrm{~N})-\end{array}$ & $\begin{array}{l}\text { SARS-CoV-2 } \\
\text { Spike- }\end{array}$ & $\begin{array}{l}\text { HEK293T } \\
\text { cells }\end{array}$ & $\begin{array}{l}0.001 \\
\mathrm{mg} / \mathrm{ml}\end{array}$ & - & $\begin{array}{l}\text { Reduced the infection rate of the } \\
\text { pseudovirus by } \sim 60 \%\end{array}$ & $\begin{array}{l}\text { 1. Reduces the risk of } \\
\text { immunogenicity }\end{array}$ & $\begin{array}{l}\text { Chatterjee et al., } \\
2020\end{array}$ \\
\hline & $\begin{array}{l}\text { CHIP } \Delta \text { TPR } \\
\text { fusion }\end{array}$ & $\begin{array}{l}\text { pseudotyped } \\
\text { lentivirus } \\
\text { infection }\end{array}$ & & & & & $\begin{array}{l}\text { 2. Can be readily synthesized } \\
\text { or be efficiently packaged for } \\
\text { delivery in a lipid nanoparticle } \\
\text { or adeno-associated virus }\end{array}$ & \\
\hline & $\begin{array}{l}\text { SAP1, } \\
\text { SAP6 }\end{array}$ & $\begin{array}{l}\text { SARS-CoV-2 } \\
\text { infection }\end{array}$ & $\begin{array}{l}\text { HEK293T- } \\
\text { ACE2-GFP } \\
\text { cells }\end{array}$ & $\begin{array}{l}3 \mathrm{mmol} / \\
\mathrm{L}\end{array}$ & - & $\begin{array}{l}\text { Resulted in } \sim 2 \text {-fold reduction in } \\
\text { SARS-CoV-2 infection }\end{array}$ & - & Larue et al., 2021 \\
\hline & $\begin{array}{l}\text { SAP1, } \\
\text { SAP6 }\end{array}$ & $\begin{array}{l}\text { HCoV-NL63 } \\
\text { infection }\end{array}$ & $\begin{array}{l}\text { LLC-MK2 } \\
\text { cells }\end{array}$ & $\begin{array}{l}3 \mathrm{mmol} / \\
\mathrm{L}\end{array}$ & - & $\begin{array}{l}\text { Resulted in } \sim 3 \text {-fold reduced } \\
\text { HCoV-NL63 titers }\end{array}$ & - & Larue et al., 2021 \\
\hline
\end{tabular}

ARDS, acute respiratory distress syndrome; NADPH, nicotinamide adenine dinucleotide phosphate; SBP, systolic blood pressure; BP, blood pressure.

Clinicaltrials, 2021; Larue et al., 2021; Wysocki et al., 2021), the understanding of SARS-CoV-2 pathogenesis is still in a developing stage. The possibility of virus making use of other receptors (e.g., tyrosine-protein kinase receptor UFO, kidney injury molecule-1 and cluster of differentiation 147), co-receptors/auxiliary proteins or even other mechanisms for entry into the cells cannot be ruled out. As the clinical manifestations of SARS-CoV-2 infection are very variable and can occur from asymptomatic infection to severe pneumonia, the appropriate drug concentrations in different patients should be explored in future research. Moreover, only the effect of hrsACE2 on early SARS-COV-2 infection is understood until now, its effect in the later stages of the disease process is still unclear, and the effects on the lungs are also poorly understood. ACE2 infusion may increase Ang-(1-7) levels and reduce circulating Ang II levels to promote infectious or cardiogenic effects in later stages of the disease. Thus, the concentration in the same patient at different stages of the treatment must be precisely adjusted to remain within the therapeutic range. Furthermore, the human body's immune response to recombinant human proteins may result in the development of neutralizing antibodies and specific $\mathrm{T}$ cell responses, thereby compromising therapeutic potential. Therefore, before these types of peptides are approved for the clinical treatment of COVID-19, sufficient data from in vitro and in vivo studies are still needed to confirm their efficacy. Additionally, except for intravenous treatment, nasal drug administration should be paid more attention because of its fast onset of action, increased bioavailability and reduced adverse reactions.

\section{DISCUSSION}

In this review, we explored how ACE2 variants and epigenetic factors influence an individual's susceptibility to SARS-CoV-2 infection and disease outcome in aspects of ethnicity, gender and age, and discussed some ACE2-based COVID-19 treatments (Figure 2). Residue changes of ACE2 in the binding interface would influence its expression and affinity with SARS-CoV-2. We compared the allele frequencies and expressions of 23 ACE2 variants in different populations, and found they could partially account for the differences in COVID-19 prevalence and mortality rates. However, in terms of affinity of the ACE2 variant to the S1 protein, current findings are controversial among studies, and the results lack validation by systems biology studies even though some variants have been believed to enhance the affinity in several reports. Thus, there is an urgent need for in vitro validation studies to assess the involvements of population-specific SNPs of ACE2 and other host factors in susceptibility toward SARS-CoV-2 infection. Moreover, we believe it is essential to promote the use of multidisciplinary tools and state-of-the-art "omics" technologies to comprehensively define the degree of inter-individual variations in susceptibility and subsequent immune responses determined by gene polymorphisms. Meanwhile, large-scale sequencing projects especially for ACE2 sequencing in the most severe patients in every population should be carried out to identify more specific susceptibility markers.

As an X-chromosome linked phenotype, the interactionbooster variants of ACE2 can have a more substantial impact on males than on females. Moreover, men lack the alternative mechanisms of organ protective functions because they have a single $\mathrm{X}$ chromosome, and this would be partially responsible for the gender bias towards a higher mortality rate in males. Furthermore, ethnicity and gender may alter the link between polymorphic variants of the ACE2 gene and a variety of diseases including hypertension, T2D, and cardiomyopathy, which represent risk factors for a severe prognosis of COVID-19. Notably, the high expression of ACE2 gene caused by 


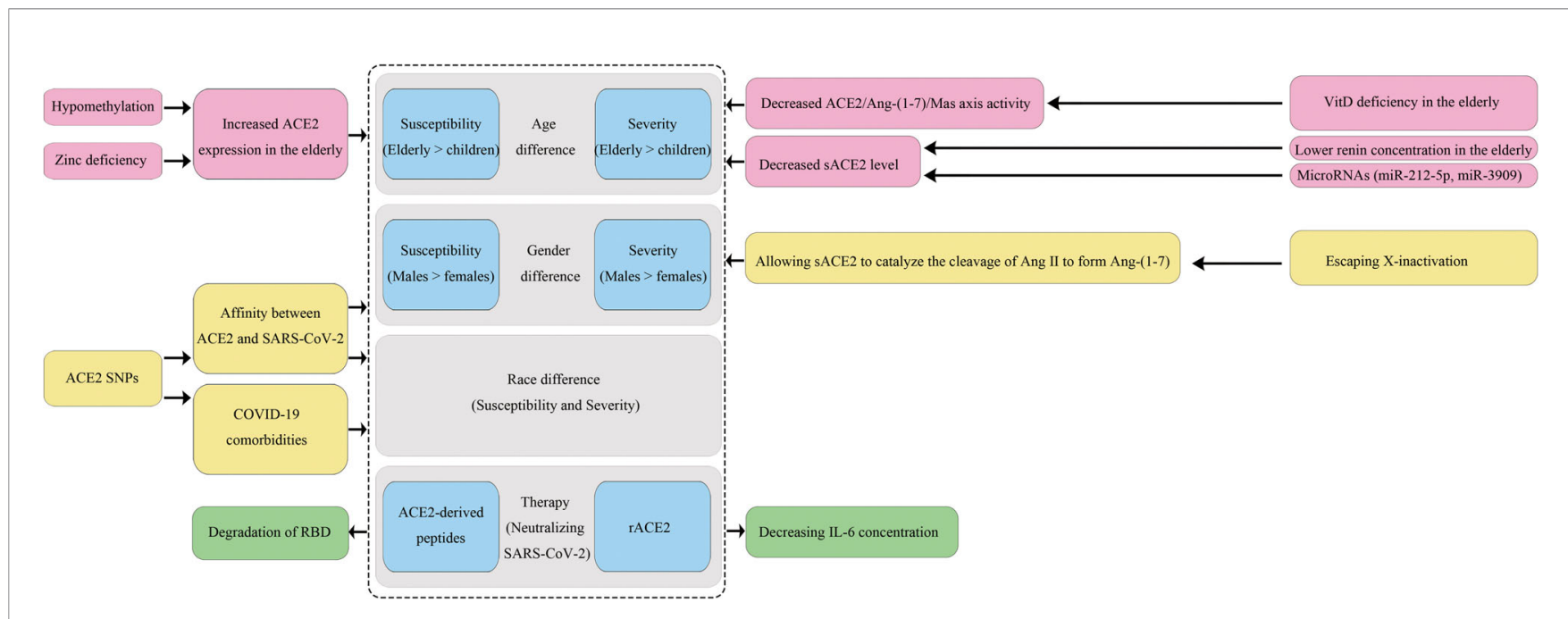

FIGURE 2 | The impact of ACE2 polymorphisms on COVID-19 disease.

hypomethylation and zinc deficiency may explain why the elderly are more sensitive to SARS-CoV-2 infection than younger populations and especially children. Moreover, their lower sACE2 and VitD levels cannot protect them from ARDS. Thus, it is reasonable to assume that stimulating specific DNA methylation of ACE2 gene could help to attenuate infection susceptibility and disease severity, and early supplements with zinc and VitD may have special benefits for elderly people. In addition, reducing age-related inflammation may decrease ACE2 expression in type II pneumocytes and limit infection of damaged alveolar epithelium. Indeed, dexamethasone and baricitinib (JAK1/2 inhibitor) have been shown to improve outcomes in COVID-19 patients. Whether these therapies bring benefits, at least in part, by regulating ACE2 expression may be a focus of future research.

Given the emergence of vaccine breakthrough infections, it is still necessary to explore effective treatment strategies and specific antiviral agents against the virus in addition to the development of vaccines. As a competitive interceptor of SARS-CoV-2, exogenous forms of sACE2 can be regarded as promising therapeutic options. Several rACE2 and ACE2derived peptides have shown acceptable safety and preliminary efficacy, but there are still some challenges to overcome, especially concerning the appropriate drug concentrations in

\section{REFERENCES}

Baker, S. A., Kwok, S., Berry, G. J., and Montine, T. J. (2021). Angiotensin-Converting Enzyme 2 (ACE2) Expression Increases With Age in Patients Requiring Mechanical Ventilation. PloS One 16, e0247060. doi: 10.1371/journal.pone.0247060 Bestle, D., Heindl, M. R., Limburg, H., Van Lam Van, T., Pilgram, O., Moulton, H., et al. (2020). TMPRSS2 and Furin are Both Essential for Proteolytic Activation of SARS-CoV-2 in Human Airway Cells. Life Sci. Alliance 3, e202000786. doi: 10.26508/lsa.202000786

Brooke, G. N., and Prischi, F. (2020). Structural and Functional Modelling of SARS-CoV-2 Entry in Animal Models. Sci. Rep. 10, 15917. doi: 10.1038/ s41598-020-72528-z different patients and the same patient at different stages of the treatment.

\section{AUTHOR CONTRIBUTIONS}

All authors contributed to the literature review for the manuscript. The first draft of the manuscript was written by FC and all authors commented on previous versions of the manuscript. All authors contributed to the article and approved the submitted version.

\section{FUNDING}

This work was supported by the Natural Science Foundation of Shandong Province (Grant no. ZR2020QC100).

\section{ACKNOWLEDGMENTS}

This is a short text to acknowledge the contributions of specific colleagues, institutions, or agencies that aided the efforts of the authors.

Cafiero, C., Rosapepe, F., Palmirotta, R., Re, A., Ottaiano, M. P., Benincasa, G., et al (2021). Angiotensin System Polymorphisms' in SARS-CoV-2 Positive Patients: Assessment Between Symptomatic and Asymptomatic Patients: A Pilot Study. Pharmgenomics Pers. Med. 14, 621-629. doi: 10.2147/PGPM.S303666

Centers for Disease Control and Prevention. (2021). Risk for COVID-19 Infection, Hospitalization, and Death By Age Group. Available at: https://www.cdc.gov/ coronavirus/2019-ncov/covid-data/investigations-discovery/hospitalizationdeath-by-age.html.

Chatterjee, P., Ponnapati, M., Kramme, C., Plesa, A. M., and Church, G. M. (2020). Targeted Intracellular Degradation of SARS-CoV-2 via Computationally Optimized Peptide Fusions. Commun. Biol. 3, 715. doi: 10.1038/s42003-02001470-7 
Chen, L., Feng, Y., Zhou, Y., Zhu, W., Shen, X., Chen, K., et al. (2010). Dual Role of $\mathrm{Zn} 2+$ in Maintaining Structural Integrity and Suppressing Deacetylase Activity of SIRT1. J. Inorg. Biochem. 104, 180-185. doi: 10.1016/j.jinorgbio.2009.10.021

Chen, Y. Y., Liu, D., Zhang, P., Zhong, J. C., Zhang, C. J., Wu, S. L., et al. (2016). Impact of ACE2 Gene Polymorphism on Antihypertensive Efficacy of ACE Inhibitors. J. Hum. Hypertens. 30, 766-771. doi: 10.1038/jhh.2016.24

Chen, L. J., Xu, Y. L., Song, B., Yu, H. M., Oudit, G. Y., Xu, R., et al. (2016). Angiotensin-Converting Enzyme 2 Ameliorates Renal Fibrosis by Blocking the Activation of mTOR/ERK Signaling in Apolipoprotein E-Deficient Mice. Peptides 79, 49-57. doi: 10.1016/j.peptides.2016.03.008

Clinicaltrials (2021) Recombinant Human Angiotensin-Converting Enzyme 2 (Rhace2) as a Treatment for Patients With COVID-19 (APN01-COVID-19). Nct04335136. Available at: https://clinicaltrials.gov/ct2/show/study/ NCT04335136?term=NCT04335136\&draw $=04335132 \&$ rank $=04335131$.

Corley, M. J., and Ndhlovu, L. C. (2020). DNA Methylation Analysis of the COVID-19 Host Cell Receptor, Angiotensin I Converting Enzyme 2 Gene (ACE2) in the Respiratory System Reveal Age and Gender Differences. Preprints 2020030295. doi: 10.20944/preprints202003.0295.v1

Darbani, B. (2020). The Expression and Polymorphism of Entry Machinery for COVID-19 in Human: Juxtaposing Population Groups, Gender, and Different Tissues. Int. J. Environ. Res. Public Health 17, 3433. doi: 10.3390/ ijerph17103433

Deshpande, A., Harris, B. D., Martinez-Sobrido, L., Kobie, J. J., and Walter, M. R. (2021). Epitope Classification and RBD Binding Properties of Neutralizing Antibodies Against SARS-CoV-2 Variants of Concern. Front. Immunol. 12, 691715. doi: 10.3389/fimmu.2021.691715

De, A., Tiwari, A., Dash, M., and Sinha, A. (2021). ACE2 Mutation Might Explain Lower COVID-19 Burden in Malaria Endemic Areas. Hum. Cell 34, 702-705. doi: 10.1007/s13577-021-00489-0

Devaux, C. A., Pinault, L., Osman, I. O., and Raoult, D. (2020b). Can ACE2 Receptor Polymorphism Predict Species Susceptibility to SARS-CoV-2? Front. Public Health 8. doi: 10.3389/fpubh.2020.608765

Devaux, C. A., Rolain, J. M., and Raoult, D. (2020a). ACE2 Receptor Polymorphism: Susceptibility to SARS-CoV-2, Hypertension, Multi-Organ Failure, and COVID-19 Disease Outcome. J. Microbiol. Immunol. Infect. 53, 425-435. doi: 10.1016/j.jmii.2020.04.015

Elemam, N. M., Hasswan, H., Aljaibeji, H., and Sulaiman, N. (2021). Circulating Soluble ACE2 and Upstream microRNA Expressions in Serum of Type 2 Diabetes Mellitus Patients. Int. J. Mol. Sci. 22, 5263. doi: 10.3390/ijms22105263

Ervin, R. B., and Kennedy-Stephenson, J. (2002). Mineral Intakes of Elderly Adult Supplement and non-Supplement Users in the Third National Health and Nutrition Examination Survey. J. Nutr. 132, 3422-3427. doi: 10.1093/jn/ 132.11 .3422

Gao, S., and Zhang, L. (2020). ACE2 Partially Dictates the Host Range and Tropism of SARS-CoV-2. Comput. Struct. Biotechnol. J. 18, 4040-4047. doi: 10.1016/j.csbj.2020.11.032

Global Health 50/50 African Population and Health Research Center, and International Center for Research on Women The COVID-19 SexDisaggregated Data Tracker. Available at: https://globalhealth5050.org/thesex-gender-and-covid-19-project/dataset/.

Gralinski, L. E., and Menachery, V. D. (2020). Return of the Coronavirus: 2019Ncov. Viruses 12, 135. doi: 10.3390/v12020135

Guo, X., Chen, Z., Xia, Y., Lin, W., and Li, H. (2020). Investigation of the Genetic Variation in ACE2 on the Structural Recognition by the Novel Coronavirus (SARS-CoV-2). J. Transl. Med. 18, 321. doi: 10.1186/s12967-020-02486-7

Gu, H., Xie, Z., Li, T., Zhang, S., Lai, C., Zhu, P., et al. (2016). AngiotensinConverting Enzyme 2 Inhibits Lung Injury Induced by Respiratory Syncytial Virus. Sci. Rep. 6, 19840. doi: 10.1038/srep19840

Hadi-Alijanvand, H., and Rouhani, M. (2020). Studying the Effects of ACE2 Mutations on the Stability, Dynamics, and Dissociation Process of SARS-CoV2 S1/hACE2 Complexes. J. Proteome Res. 19, 4609-4623. doi: 10.1021/ acs.jproteome.0c00348

Haschke, M., Schuster, M., Poglitsch, M., Loibner, H., Salzberg, M., Bruggisser, M., et al. (2013). Pharmacokinetics and Pharmacodynamics of Recombinant Human Angiotensin-Converting Enzyme 2 in Healthy Human Subjects. Clin. Pharmacokinet. 52, 783-792. doi: 10.1007/s40262-013-0072-7

Heaney, R. P. (2006). Barriers to Optimizing Vitamin D3 Intake for the Elderly. J. Nutr. 136, 1123-1125. doi: 10.1093/jn/136.4.1123
He, J., Lu, Y. P., Li, J., Li, T. Y., Chen, X., Liang, X. J., et al. (2018). Fetal But Not Maternal Angiotensin Converting Enzyme (ACE)-2 Gene Rs2074192 Polymorphism is Associated With Increased Risk of Being a Small For Gestational Age (SGA) Newborn. Kidney Blood Press Res. 43, 1596-1606. doi: $10.1159 / 000494449$

Khan, A., Benthin, C., Zeno, B., Albertson, T. E., Boyd, J., Christie, J. D., et al. (2017). A Pilot Clinical Trial of Recombinant Human Angiotensin-Converting Enzyme 2 in Acute Respiratory Distress Syndrome. Crit. Care 21, 234. doi: 10.1186/s13054-017-1823-x

Kuba, K., Imai, Y., Ohto-Nakanishi, T., and Penninger, J. M. (2010). Trilogy of ACE2: A Peptidase in the Renin-Angiotensin System, a SARS Receptor, and a Partner for Amino Acid Transporters. Pharmacol. Ther. 128, 119-128. doi: 10.1016/j.pharmthera.2010.06.003

Kumar, A., Rani, B., Sharma, R., Kaur, G., Prasad, R., Bahl, A., et al. (2018). ACE2, CALM3 and TNNI3K Polymorphisms as Potential Disease Modifiers in Hypertrophic and Dilated Cardiomyopathies. Mol. Cell Biochem. 438, 167174. doi: 10.1007/s11010-017-3123-9

Lan, J., Ge, J., Yu, J., Shan, S., Zhou, H., Fan, S., et al. (2020). Structure of the SARSCoV-2 Spike Receptor-Binding Domain Bound to the ACE2 Receptor. Nature 581, 215-220. doi: 10.1038/s41586-020-2180-5

Larue, R. C., Xing, E., Kenney, A. D., Zhang, Y., Tuazon, J. A., Li, J., et al. (2021). Rationally Designed ACE2-Derived Peptides Inhibit SARS-CoV-2. Bioconjug. Chem. 32, 215-223. doi: 10.1021/acs.bioconjchem.0c00664

Lieb, W., Graf, J., Gotz, A., Konig, I. R., Mayer, B., Fischer, M., et al. (2006). Association of Angiotensin-Converting Enzyme 2 (ACE2) Gene Polymorphisms With Parameters of Left Ventricular Hypertrophy in Men. Results of the MONICA Augsburg Echocardiographic Substudy. J. Mol. Med. (Berl.) 84, 88-96. doi: 10.1007/s00109-005-0718-5

Li, M. Y., Li, L., Zhang, Y., and Wang, X. S. (2020). Expression of the SARS-CoV-2 Cell Receptor Gene ACE2 in a Wide Variety of Human Tissues. Infect. Dis. Poverty 9, 45. doi: 10.1186/s40249-020-00662-x

Liu, C., Li, Y., Guan, T., Lai, Y., Shen, Y., Zeyaweiding, A., et al. (2018). ACE2 Polymorphisms Associated With Cardiovascular Risk in Uygurs With Type 2 Diabetes Mellitus. Cardiovasc. Diabetol. 17, 127. doi: 10.1186/s12933-0180771-3

Liu, C., Pei, J., Lai, Y., Guan, T., Zeyaweiding, A., Maimaiti, T., et al. (2021). Association of ACE2 Variant Rs4646188 With the Risks of Atrial Fibrillation and Cardioembolic Stroke in Uygur Patients With Type 2 Diabetes. BMC Cardiovasc. Disord. 21, 103. doi: 10.1186/s12872-021-01915-9

Liu, P., Wysocki, J., Souma, T., Ye, M., Ramirez, V., Zhou, B., et al. (2018). Novel ACE2-Fc Chimeric Fusion Provides Long-Lasting Hypertension Control and Organ Protection in Mouse Models of Systemic Renin Angiotensin System Activation. Kidney Int. 94, 114-125. doi: 10.1016/j.kint.2018.01.029

Lopera Maya, E. A., van der Graaf, A., Lanting, P., van der Geest, M., Fu, J., Swertz, M., et al. (2020). Lack of Association Between Genetic Variants at ACE2 and TMPRSS2 Genes Involved in SARS-CoV-2 Infection and Human Quantitative Phenotypes. Front. Genet. 11, 613. doi: 10.3389/fgene.2020.00613

Lozano-Gonzalez, K., Padilla-Rodriguez, E., Texis, T., Gutierrez, M. N., Rodriguez-Dorantes, M., Cuevas-Cordoba, B., et al. (2020). Allele Frequency of ACE2 Intron Variants and Its Association With Blood Pressure. DNA Cell Biol. 39, 2095-2101. doi: 10.1089/dna.2020.5804

Luo, Y., Liu, C., Guan, T., Li, Y., Lai, Y., Li, F., et al. (2019). Association of ACE2 Genetic Polymorphisms With Hypertension-Related Target Organ Damages in South Xinjiang. Hypertens. Res. 42, 681-689. doi: 10.1038/ s41440-018-0166-6

Mauvais-Jarvis, F. (2020). Aging, Male Sex, Obesity, and Metabolic Inflammation Create the Perfect Storm for COVID-19. Diabetes 69, 1857-1863. doi: 10.2337/ dbi19-0023

Meng, N., Zhang, Y., Ma, J., Li, H., Zhou, F., and Qu, Y. (2015). Association of Polymorphisms of Angiotensin I Converting Enzyme 2 With Retinopathy in Type 2 Diabetes Mellitus Among Chinese Individuals. Eye (Lond.) 29, 266-271. doi: 10.1038/eye.2014.254

Mohlendick, B., Schonfelder, K., Breuckmann, K., Elsner, C., Babel, N., Balfanz, P., et al. (2021). ACE2 Polymorphism and Susceptibility for SARS-CoV-2 Infection and Severity of COVID-19. Pharmacogenet. Genomics 31, 165-171. doi: 10.1097/FPC.0000000000000436

Monteil, V., Kwon, H., Prado, P., Hagelkruys, A., Wimmer, R. A., Stahl, M., et al. (2020). Inhibition of SARS-CoV-2 Infections in Engineered Human Tissues 
Using Clinical-Grade Soluble Human Ace2. Cell 181, 905-913 e907. doi: 10.1016/j.cell.2020.04.004

Othman, H., Bouslama, Z., Brandenburg, J. T., Da Rocha, J., Hamdi, Y., Ghedira, K., et al. (2020). Interaction of the Spike Protein RBD From SARS-CoV-2 With ACE2: Similarity With SARS-CoV, Hot-Spot Analysis and Effect of the Receptor Polymorphism. Biochem. Biophys. Res. Commun. 527, 702-708. doi: 10.1016/j.bbrc.2020.05.028

Pan, Y., Wang, T., Li, Y., Guan, T., Lai, Y., Shen, Y., et al. (2018). Association of ACE2 Polymorphisms With Susceptibility to Essential Hypertension and Dyslipidemia in Xinjiang, China. Lipids Health Dis. 17, 241. doi: 10.1186/ s12944-018-0890-6

Patel, V. B., Zhong, J. C., Grant, M. B., and Oudit, G. Y. (2016). Role of the ACE2/ Angiotensin 1-7 Axis of the Renin-Angiotensin System in Heart Failure. Circ. Res. 118, 1313-1326. doi: 10.1161/CIRCRESAHA.116.307708

Pruimboom, L. (2020). Methylation Pathways and SARS-CoV-2 Lung Infiltration and Cell Membrane-Virus Fusion Are Both Subject to Epigenetics. Front. Cell Infect. Microbiol. 10, 290. doi: 10.3389/fcimb.2020.00290

Rathinasabapathy, A., Bryant, A. J., Suzuki, T., Moore, C., Shay, S., Gladson, S., et al. (2018). Rhace2 Therapy Modifies Bleomycin-Induced Pulmonary Hypertension via Rescue of Vascular Remodeling. Front. Physiol. 9, 271. doi: 10.3389/fphys.2018.00271

Sawalha, A. H., Zhao, M., Coit, P., and Lu, Q. (2020). Epigenetic Dysregulation of ACE2 and Interferon-Regulated Genes Might Suggest Increased COVID-19 Susceptibility and Severity in Lupus Patients. Clin. Immunol. 215, 108410. doi: 10.1016/j.clim.2020.108410

Sehailia, M., and Chemat, S. (2020). Antimalarial-Agent Artemisinin and Derivatives Portray More Potent Binding to Lys353 and Lys31-Binding Hotspots of SARS-CoV-2 Spike Protein Than Hydroxychloroquine: Potential Repurposing of Artenimol for COVID-19. J. Biomol. Struct. Dyn. 39, 61846194. doi: 10.1080/07391102.2020.1796809

Sulaiman, K. A., Alhubaishi, A., Juhani, O. A., Eljaaly, K., Harbi, O. A., Badreldin, H. A., et al. (2021). Early Versus Late Use of Dexamethasone in Critically Ill Patients With Covid-19: A Multicenter, Prospective Cohort Study. Preprint. doi: 10.21203/rs.3.rs-349677/v1

Suryamohan, K., Diwanji, D., Stawiski, E. W., Gupta, R., Miersch, S., Liu, J., et al. (2021). Human ACE2 Receptor Polymorphisms and Altered Susceptibility to SARS-CoV-2. Commun. Biol. 4, 475. doi: 10.1038/s42003-021-02030-3

Wang, S. X., Fu, C. Y., Zou, Y. B., Wang, H., Shi, Y., Xu, X. Q., et al. (2008). Polymorphisms of Angiotensin-Converting Enzyme 2 Gene Associated With Magnitude of Left Ventricular Hypertrophy in Male Patients With Hypertrophic Cardiomyopathy. Chin. Med. J. (Engl.) 121, 27-31. doi: 10.1097/00029330-200801010-00006
Wang, J., Xu, X., Zhou, X., Chen, P., Liang, H., Li, X., et al. (2020). Molecular Simulation of SARS-CoV-2 Spike Protein Binding to Pangolin ACE2 or Human ACE2 Natural Variants Reveals Altered Susceptibility to Infection. J. Gen. Virol. 101, 921-924. doi: 10.1099/jgv.0.001452

Wan, Y., Shang, J., Graham, R., Baric, R. S., and Li, F. (2020). Receptor Recognition by the Novel Coronavirus From Wuhan: An Analysis Based on Decade-Long Structural Studies of SARS Coronavirus. J. Virol. 94, e00127-20. doi: 10.1128/ JVI.00127-20

WHO (2021) WHO Coronavirus Disease (COVID19) Dashboard. Available at: https://covid19.who.int/.

Wysocki, J., Ye, M., Hassler, L., Gupta, A. K., Wang, Y., Nicoleascu, V., et al (2021). A Novel Soluble ACE2 Variant With Prolonged Duration of Action Neutralizes SARS-CoV-2 Infection in Human Kidney Organoids. J. Am. Soc. Nephrol. 32, 795-803. doi: 10.1681/ASN.2020101537

Yi, L., Gu, Y. H., Wang, X. L., An, L. Z., Xie, X. D., Shao, W., et al. (2006). Association of ACE, ACE2 and UTS2 Polymorphisms With Essential Hypertension in Han and Dongxiang Populations From North-Western China. J. Int. Med. Res. 34, 272-283. doi: 10.1177/147323000603400306

Zhong, J., Guo, D., Chen, C. B., Wang, W., Schuster, M., Loibner, H., et al. (2011). Prevention of Angiotensin II-Mediated Renal Oxidative Stress, Inflammation, and Fibrosis by Angiotensin-Converting Enzyme 2. Hypertension 57, 314-322. doi: 10.1161/HYPERTENSIONAHA.110.164244

Zou, Z., Yan, Y., Shu, Y., Gao, R., Sun, Y., Li, X., et al. (2014). AngiotensinConverting Enzyme 2 Protects From Lethal Avian Influenza A H5N1 Infections. Nat. Commun. 5, 3594. doi: 10.1038/ncomms4594

Conflict of Interest: The authors declare that the research was conducted in the absence of any commercial or financial relationships that could be construed as a potential conflict of interest.

Publisher's Note: All claims expressed in this article are solely those of the authors and do not necessarily represent those of their affiliated organizations, or those of the publisher, the editors and the reviewers. Any product that may be evaluated in this article, or claim that may be made by its manufacturer, is not guaranteed or endorsed by the publisher.

Copyright $\odot 2021$ Chen, Zhang, Li, Li, Liu and Xue. This is an open-access article distributed under the terms of the Creative Commons Attribution License (CC BY). The use, distribution or reproduction in other forums is permitted, provided the original author(s) and the copyright owner(s) are credited and that the original publication in this journal is cited, in accordance with accepted academic practice. No use, distribution or reproduction is permitted which does not comply with these terms. 